\title{
Paoliida, a putative stem-group of winged insects: Morphology of new taxa from the Upper Carboniferous of Poland
}

Jakub Prokop, Wiesław Krzemiński, Ewa Krzemińska, and Dariusz Wojciechowski

Acta Palaeontologica Polonica 57 (1), 2012: 161-173 doi: http://dx.doi.org/10.4202/app.2010.0064

New representatives of a stem group Paoliida attributed to family Paoliidae (Insecta: Protoptera) are described from the Upper Carboniferous (Langsettian) sphero-sideritic concretions of the Upper Silesian Coal Basin (USCB) in Poland. Zdenekia silesiensis sp. nov. is based on forewing venation and supplemented by material of isolated hindwing similar in venation pattern. Darekia sanguinea gen. et sp. nov. differs from all other paoliid genera by the presence of a short contact between veins MP and $\mathrm{CuA}$ behind the division $\mathrm{CuA}$ and $\mathrm{CuP}$. Composition of insect fauna exhibits high abundance of paoliid insects in the early Late Carboniferous ecosystems known also from other European localities such as Hagen Vorhalle in Ruhr Basin (Germany), and South Limbourg (Belgium and the Netherlands). It is the first record of true paoliids from the Polish part of paralic USCB supplementing a single historical record of Stygne roemeri considered as a taxon closely related to Paoliidae. The high abundance of paoliid insects from sphero-sideritic concretions in Sosnowiec and coal deposits previously known from the Czech part of Upper Silesian Coal Basin indicates considerable similarity of both faunas supported as well by their close stratigraphical correlation. Morphology of basal wing parts with remnants of articular sclerites preserved supports neopteran relationships of paoliids. Discovery of the first paoliid immature wing is reported suggesting similar living habitat for larvae and adults.

Key words: Insecta, Neoptera, Protoptera, Paoliidae, wing articulation, Langsettian, Upper Silesian Coal Basin, Poland.

Jakub Prokop [jprokop@natur.cuni.cz], Charles University in Prague, Faculty of Science, Department of Zoology, Viničná 7 , CZ-128 44, Praha 2, Czech Republic. Wiesław Krzemiński [krzeminski@muzeum.pan.krakow.pl ], Ewa Krzemińska [krzeminska@isez.pan.krakow.pl], and Dariusz Wojciechowski [d.wojciechowski@poczta.fm], Institute of Systematics and Evolution of Animals, Polish Academy of Sciences, Sławkowska 17, 31016 Kraków, Poland. 
This is an open-access article distributed under the terms of the Creative Commons

Attribution License (for details please see creativecommons.org), which permits unrestricted use, distribution, and reproduction in any medium, provided the original author and source are credited.

FoF 